\title{
FACTORS ASSOCIATED WITH DIARRHEA IN NOEBEBA, MIDDLE SOUTH TIMOR, EAST NUSA TENGGARA
}

\author{
Denisius Umbu Pati') Pius Weraman²) Hari Rarindo ${ }^{2)}$ \\ 1)Masters Program in Public Health, Universitas Nusa Cendana \\ 2)Universitas Kristen Wira Wacana Sumba \\ 3)Faculty of Public Health, Universitas Nusa Cendana
}

\begin{abstract}
Background: Acute diarrheal diseases remain a leading cause of global morbidity and mortality particularly among young children in resource-limited countries. Large studies are also currently underway evaluating novel and potential easy-toimplement water sanitation and hygiene (WASH) preventive strategies. This study aimed to examine factors associated with diarrhea in Noebeba, South Timor Tengah.

Subjects and Method: This was a cross-sectional study conducted in Noebeba, Middle South Timor, East Nusa Tenggara. A sample of 355 mothers was selected for this study by simple random sampling. The dependent variable was diarrhea. The independent variables were household water container ownership, latrine ownership, maternal knowledge, handwashing practice, trash bin, and food sanitation. The data were collected by questionnaire. The data were analyzed by a multiple logistic regression.

Results: Household water container ownership ( $O R=0.21 ; p=0.003)$, latrine ownership ( $\mathrm{OR}=0.32 ; \mathrm{p}<0.001)$, good maternal knowledge $(\mathrm{OR}=0.62 ; \mathrm{p}<0.001)$, and handwashing practice $(\mathrm{OR}=0.41 ; \mathrm{p}<0.001)$ were associated with a decreased incidence of diarrhea. Trash bin and food sanitation did not show statistical significance with incidence of diarrhea.

Conclusion: Household water container ownership, latrine ownership, good maternal knowledge, and handwashing practice, are associated with a decreased incidence of diarrhea.
\end{abstract}

Keywords: diarrhea, hygiene, sanitation, risk factors

\section{Correspondence:}

Denisius Umbu Pati. Masters Program in Public Health, Universitas Nusa Cendana/ Universitas Kristen Wira Wacana Sumba, Kupang, East Nusa Tenggara. Email: umbudenis@gmail.com. Mobile: 082237754329 